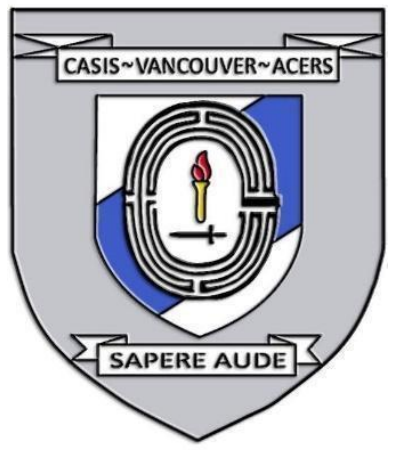

\title{
GEN Z AS SECURITY CONTENT CREATORS: RECREATING THE TERMS OF THE SOCIAL CONTRACT
}

Date: November $27^{\text {th }}, 2020$

Disclaimer: This briefing note contains the encapsulation of views presented by the speaker and does not exclusively represent the views of the Canadian Association for Security and Intelligence Studies.

\section{KEY EVENTS}

On November 27, 2020, Natalie Archutowski and Serge Bergler presented on the topic of Generation Z (Gen Z) as security content creators, at the 2020 CASIS West Coast Security Conference. The presentation was followed by a question and answer period. Key points of discussion included: Narrative control, framing and influencer activity, generational differences, ethics, and what role gen $\mathrm{Z}$ plays in forming emerging social and security norms.

\section{NATURE OF DISCUSSION}

\section{Presentation}

Natalie Archutowski and Serge Bergler discussed the topic of Gen Z's; why they have different perspectives, their creation of a unique identity rather than one imposed on them, identity fluidity, and what role they might play in shaping today and tomorrow's social landscape.

\section{Question Period}

During the question period, the discussion primarily focused on the fluidity of identity, content creation as a potential security concern, and how to better understand what differentiates Gen $\mathrm{Z}$ from other generations.

\section{BACKGROUND}

\section{Presentation}

Gen Z's ability to take control of their narrative arguably comes from their avid technological proficiency. They are able to take control, create, and disseminate their own specific narratives. An argument can be made that due to their technological proficiency and need for fast paced change they are able to make conscious strategic efforts to fashion shared understandings of the world to 
legitimize and motivate collective action for issues that are transnational by nature (McAdam \& McCarthy, 1996). It can be said that this framing is what allows them to be dictating and shaping tomorrow by changing the norms of today. This arguably presents challenges seeing as arguably Gen $\mathrm{Z}$ is changing the way we need to think about security.

Another challenge that seems to be present is the fact that there are major generational differences from any generation prior. Gen Z's have mass volumes of data, data sets, and AI algorithms at their fingertips. They have computational power at their disposal, as well as an array of communication mediums at their command and have access to social media which serves as an echo chamber, amongst many other differences. It can be argued that they are instinctively distinct from other generations based on their core values and sense of identities, which are arguably no different whether they are online or offline whilst being dynamic as they do not limit themselves to one identity. Francis and Hoefel (2018) add that they can possibly be seen as a hypercognitive generation that is comfortable with collecting and cross referencing many sources of information whilst integrating both their virtual and offline experiences.

It is argued that Gen $\mathrm{Z}$ is a generation of content creators who shape and dictate dialogue and systemic norms with over $75 \%$ of Generation $\mathrm{Z}$ wanting to become Youtubers (Mediakix, 2020). Arguably, they are not willing to allow perceived wrongs to remain, and therefore, actively seek to disrupt and revolutionize perceptions of injustice. It is possible that they act based on clearly considered mobilization plans for achieving end goals using the power of the internet and social activism. Through their technological proficiency they are able to actively spread messages and influence others in the virtual world. Gen Zs are arguably more likely to participate and associate themselves with Violent Transnational Social Movements (VTSMs), but equally with activist social movements which are non-violent and promote equality and equity.

It can be said that ethics are as important to Gen Zs as saving money was and is arguably more important to millennials. Gen Zs can be said to be principled, ethical, and critical and will not shop with, work with, or use products or entertainment from unprincipled producers and creators; they would rather create their own content. Alongside this, it can be said that they are focused on achieving equity, equality, justice, and accountability. With that being said an argument can be made that Gen Zs are influencers, activists, messengers, and actors in the movements that are being redesigned with the 21 st century. When one uses the word Radical or Revolutionary and applies it to this generation it shows that they can also run on the opposite side of the pendulum. Gen Zs have also been physical and kinetic activists, online transnational advocacy network influencers, messengers, and violent actors who are creators of, driven by and express the sentiments of the social movements with whom they identify. 
As previously stated, Gen Zs do not limit themselves to one iteration in identity choices, and arguably by labeling them domestic terrorists or anarchists does not help in addressing the issues. The adopted identities and movements individual Gen Zs are aligned with might be considered mobile and dynamic. Socially inclusive Gen Zs also appear to be less likely to commit physical or kinetic violence, though they appear to be comfortable with committing acts of soft violence. Inclusive social movements might be understood as identity-based actors who seek to disrupt or change aspects of existing social cultural relational and structural norms as a means of obtaining greater justice or equality in an existing system. Exclusive violent identity-based actors who seek to maintain and defend existing social cultural and structural norms as a means of ensuring continued relevance, privilege, dominance, and authority. Individuals who identify with violence, regardless of their generational and other affiliations, consume soft violence messaging and might become prone to acting as a result of the echo chambers they frequent.

As a generational actor with technological fluency blurring the boundaries between online and offline spheres, with communication and messaging mastery, it can be said that Gen Zs social role is distinctively different from previous generations. Gen Zs can arguably act as transnational advocacy networks with the explicit intention of not maintaining or changing culture but of creating new social contracts and new dialogues. This involves creating and disseminating the content and narrative which they intend to live into. This creation of new social contracts implies the recognition of the old. Gen Zs arguably seek change as narrated by clear and consistent messaging which is succinct and easily embraced by wider swathes of civil society who experience injustice and inequality. It can be said that they do not go to war or seek to destroy order; they simply wish to amend it for better equality, justice, and equity.

Gen Z's media consumption habits seem to differ from previous generations. As content creators they arguably have a unique opportunity to shape and dictate the cultural dialogue and the consequent shift in norms within civil society. Activism may not be viewed as a political choice, but an existential imperative by Gen Z's. They are willing to accept unjust status quos or creeping normalcy of authoritarian oppression or domination in any form. Furthermore, they are not willing to accept unjust status quos, creeping normalcy of authoritarian oppression, and domination in any form or injustice. However, this does not mean they are a security threat, it means these issues are important to them and a lack of discussion results in action.

With that being said, Gen Zs arguably act as Transnational Advocacy Networks (TANs) by creating and adapting to content. Their use of technology is underscored by a shift in generational values of content creation, identity fluidity, activism, and social awareness. Activism should not be seen as a security problem; it is a signaling of intention of normative change. Security services 
might consider avoiding the temptation to see Gen Zs as haphazard, but instead as seeking safety and quality. They might be seen as wanting to reshape and redesign social and civic contracts.

Gen Zs arguably use and create social movements to generate momentum and achieve their specific goals through the use of technology, identity-based sympathies, and popular support. Gen Zs do not merely disrupt and share slogans, instead they share guidelines on the methods of bringing about social change allowing momentum to build without explicit instructions or command structures. It can be said that this entire generation is plugged into contributing and creating online activity as part of their existential existence and thus acting as a norm shifting social movement with vast non territorial reach and an amplified communication opportunity via echo chamber repeaters instead of cellular repeaters which previous generations were limited to (Campbell et al., 2019). It can be said that Gen Zs as a generation are inclusive in terms of sexuality, race, demographics, economic standing, and human rights. They are fluid in their belief systems and resist labeling.

\section{Question Period}

When taking into account that approximately $50 \%$ of Gen Zs are connected to the internet for 10 or more hours a day, the array of datasets available to them and the echo chamber effect is a potential security concern that might become prominent with the increased likelihood of mass identity manipulation that occurs at times within transnational advocacy networks for exclusive social movements (Moskalenko \& McCauley, 2020). The echo chamber effect allows individuals unparalleled access to read similar literature on any topic they wish to learn on, which can come from non-traditional sources such as short videos and extremist memes.

Both post modernism and VTSM theory arguably demonstrate that identity is not just being created from the top down with new sources. It is coming from the bottom up now and being created by the people who are living their lives and experiencing the world, rather than solely relying on traditional media sources. This arguably allows Gen Zs not only to find validity in their opinions by people who share similar worldviews, resulting in the creation of online communities that can transition offline for action on behalf of both inclusive and exclusive social movements.

\section{KEY POINTS OF DISCUSSION}

\section{Presentation}

- Gen $\mathrm{Z}$ is arguably unique in that they believe in creating their own identity that is dynamic and evolving - they do not want an identity imposed on them. 
- For Gen Z, fluidity is positive and fixed sexuality and traditional social norms, expectations, and roles are burdens to be shrugged off.

- Gen Z's have arguably taken on more social roles as content creators, influencers, and activists, which might be seen as Transnational Advocacy Networks (TANs). These Gen Zs might be seen as falling into inclusive or exclusive social movements. With the former advocating for equity, justice, and equality, while the latter arguably act in pursuit of legitimacy, authority, dominance, and supremacy of one identity group over another.

\section{Question Period}

- A potential key security concern that might become prominent with Gen $\mathrm{Z}$ is the possible increased likelihood of mass identity manipulation that arguably occurs within transnational advocacy networks for exclusive social movements (Moskalenko \& McCauley, 2020).

- Gen Zs might be seen as adept at using their connectivity to influence, advocate, and mobilize social movements for inclusive or exclusive purposes.

- Identity is not just being created from the top down with new sources. It is being created by the people who are living their lives and experiencing the world rather than solely relying on traditional media sources. 


\section{References}

Campbell, D., Al-Rawi, A., Kelshall, C., \& Taboada, M. (2019, December 11). Predicting Escalation to Violence using Social Media Posing. Big Data at SFU._https://www.sfu.ca/big-data/predicting-escalation-violenceusing-social-media-posing

Francis, T., \& Hoefel, F. (2018, November 12). "True Gen”: Generation Z and its implications for companies. McKinsey \& Company. https://www.mckinsey.com/industries/consumer-packaged-goods/ourinsights/true-gen-generation-z-and-its-implications-for-companies\#

McAdam, D., McCarthy, J. D., \& Zald, M. N. (Eds.). (1996). Comparative perspectives on social movements: political opportunities, mobilizing structures, and cultural framings. Cambridge University Press. https://doi.org/10.1017/CBO9780511803987

Mediakix. (n.d.). Why children are set on becoming YouTubers when they grow up. https://mediakix.com/blog/percent-children-becoming-a-youtuber/

Moskalenko, S., \& McCauley, C. (2020). What are mass identity manipulation (MIMs) - pictures, songs/chants, rumors, rituals and symbols? In Radicalization to terrorism: What everyone needs to know. Oxford University Press. https://doi.org/10.1093/wentk/9780190862596.001.0001

\section{c) (†) $\ominus$}

EY No ND This work is licensed under a Creative Commons AttributionNonCommercial-NoDerivatives 4.0 International License.

(C) (Natalie Archutowski \& Serge Bergler, 2021)

Published by the Journal of Intelligence, Conflict, and Warfare and Simon Fraser University Available from: https://jicw.org/ 